\title{
Abnormalities of gut vessels in Turner's syndrome
}

\author{
WALTER H. REINHART \\ M.D.
}

MAX STÄUBLI

M.D.
CARLO MORDASINI
M.D.

ULRICH SCHEURER

M.D.

Gastrointestinal Unit and Department of Internal Medicine, University of Berne, Inselspital, 3010 Berne, Switzerland

\section{Summary}

\begin{abstract}
We describe a 57-year-old patient with Turner's syndrome, iron deficiency anaemia and intestinal vascular abnormalities. Colonoscopy revealed 2 widely dilated, tortuous veins in the terminal ileum and several smaller ectatic veins and haemangiomalike malformations throughout the colon. Laparotomy for herniotomy showed only minimal vascular abnormalities of the serosal surface. Patients with Turner's syndrome and anaemia should be checked for these lesions by endoscopy, and conversely, in patients with such lesions, Turner's syndrome should be considered.
\end{abstract}

KEY WORDS: Turner's syndrome, anaemia, gut vessel abnormalities.

\section{Introduction}

In 1938, Turner published his classical paper describing a congenital disorder associated with gonadal dysgenesis, webbed neck and cubitus valgus. Further abnormalities associated with the same syndrome have been described since then (Haddad and Wilkins, 1959). An association of Turner's syndrome with gastrointestinal haemorrhage due to haemangiomas, was described by Lisser et al. (1947). Since then, 23 cases have been reported, most of them having been discovered at laparotomy. Diagnosis was made by endoscopy in a few cases only (Rutlin et al., 1981; Rosen, Sirota and Marinoff, 1967). We describe a patient with Turner's syndrome and gastrointestinal bleeding probably due to vascular abnormalities, discovered by endoscopy.

\section{Case report}

A 57-year-old unmarried kitchen aid was admitted to the hospital in October 1981 with anaemia. In 1972 appendicectomy had been performed. In 1974, at the age of 50, diagnosis of Turner's syndrome with hypogonadism, primary amenorrhoea and a typicå dysmorphic habitus was made. Sex chromatin w completely absent in leucocytes, in the mucosa of the mouth and in the roots of the hair. Hormonal substitution was not given. In 1978 , she had a right sided inguinal hernia repair which recurred a fei weeks later. She presented in July 1981 with a month history of fatigue and was found to anaemic. The haemoglobin was $9.0 \mathrm{~g} / \mathrm{dl}$, and the reticulocyte count was $0.8 \%$. The white cell count platelets were normal.

No stainable iron was found in the bone marm Stool examination for occult blood was positive times. On gastroscopy, several spots of intestin metaplasia were found in the antrum and proven ty histological examination. Colonoscopy showed very tortuous, varix-like veins in the terminal ileung, several centimeters in length with a diameter of abou $7 \mathrm{~mm}$ (Fig. 1). There was no active bleeding during endoscopy. Throughout the colon several similat abnormalities were found, although much smaller size. Furthermore, some blue strawberry-like prom nent abnormalities with a maximum diameter of $\bar{s}$ $\mathrm{mm}$ were observed. A selective small bowel series revealed no abnormality; varix-like veins could nô be detected.

The patient was discharged on iron replacemen therapy. One month later the haemoglobin had risen to $11.9 \mathrm{~g} / \mathrm{dl}$. At operation to repair the hernia, the serosal surface of the terminal ileum and colon showed only minor vascular abnormalities, some very thin but tortuous vessels near the mesenter Tortuous veins shone through the intestinal wall the ileum (Fig. 2).

\section{Discussion}

The intestinal vascular abnormalities seen in this patient seem to be sufficiently characteristic to rais 


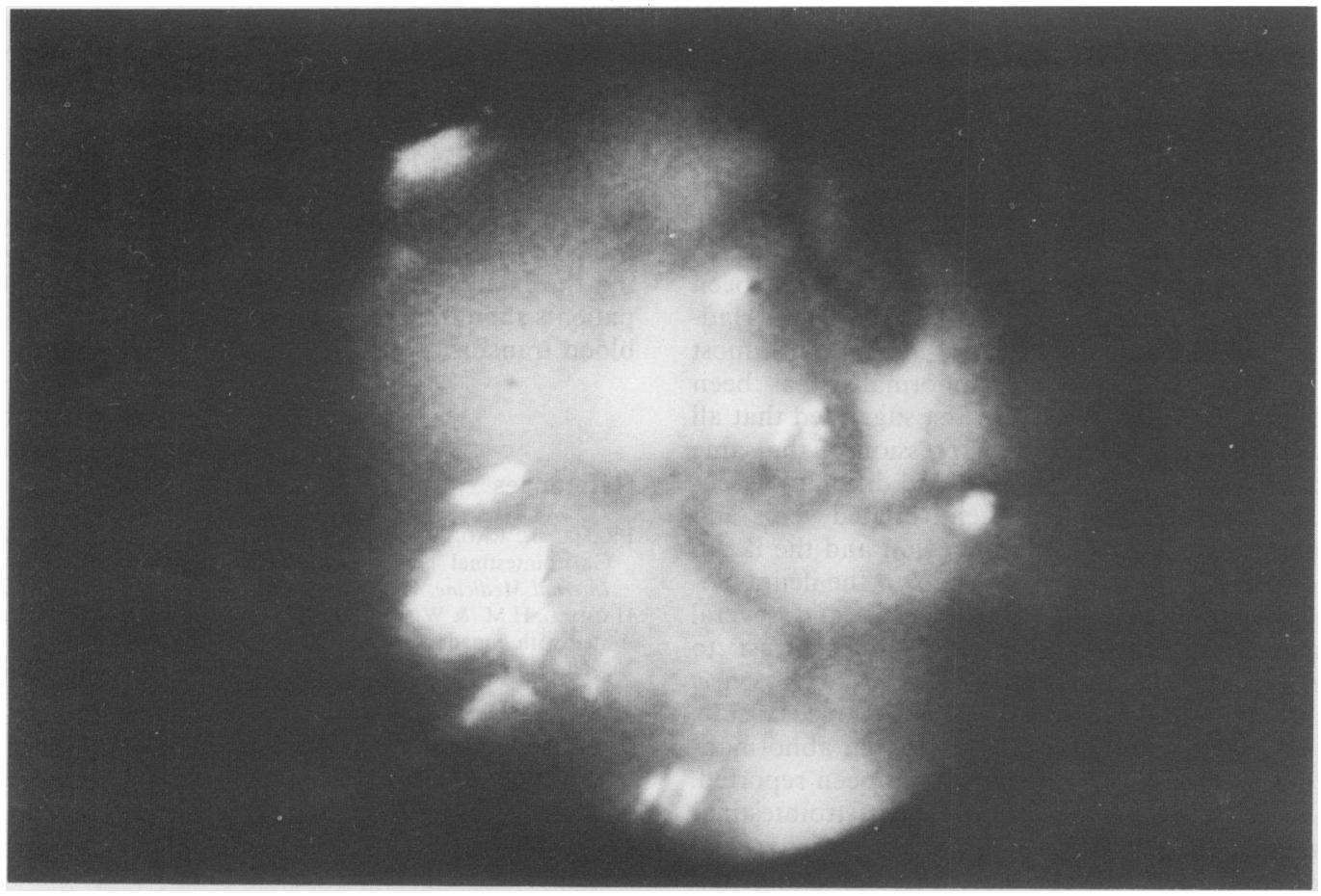

FIG. 1. Endoscopic view of tortuous varix-like vein in the terminal ileum (diameter about $7 \mathrm{~mm}$ ) in a patient with Turner's syndrome (Endoscope: Olympus CF IBW, videocamera: ITC Ikegami. Tsushinki Co. Ltd., Japan.)

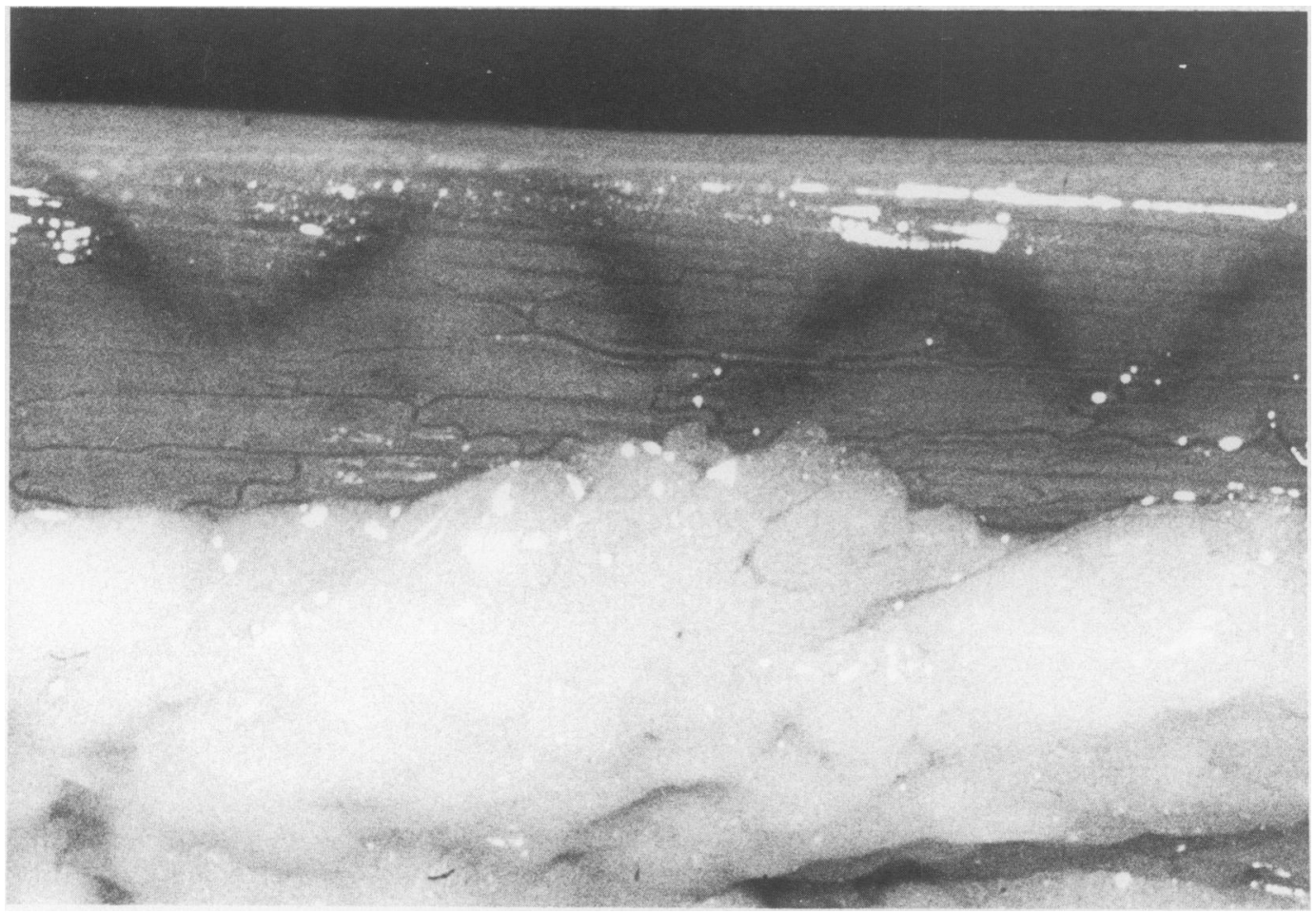

FIG. 2. Tortuous veins shining through the intestinal wall of the ileum at laparotomy in the same patient. The serosal layer is normal. 
the possibility present in female patients of Turner's syndrome (Rosen et al., 1967). Similar vascular abnormalities have not been described in men. Other causes of ectatic veins, such as portal hypertension, were excluded. To our knowledge, only 23 such cases have been published to date. Haddad and Wilkins (1959) examined 56 patients with Turner's syndrome and found a prevalence of vascular lesions of about 5 to $8 \%$. Ectatic veins or haemangiomas have been described, predominantly on the serosal side (Haddad and Wilkins, 1959; Rosen et al., 1967). In most patients, only one type of abnormality has been described. Rosen et al. (1967) first suggested that all these varieties could be the expression of the same vascular anomaly. In fact, we found different vascular abnormalities in our patient, dilated veins and venules at different sites in the colon and the ileum with extremely gross varicose veins in the ileum (socalled 'bag of worms'), telangiectasia and several haemangioma-like malformations. In contrast to other reports (Haddad and Wilkins, 1959; Rosen et al., 1967), the lesions were only on the mucosal side. The endoscopic finding of these vascular abnormalities in the terminal ileum has not yet been reported.

Routine X-ray examination of the gastrointestinal tract, including selective small bowel series, is not adequate to demonstrate these vascular malformations (Frame et al., 1977), as in our case. Angiography was not performed in the present case, and, with the size of the vessels seen, some abnormality might have been expected.
Bleeding seems to be intermittent, and intestingl haemorrhage apparently tends to decrease in severity and frequency with age (Frame et al., 1977). regression of these vascular abnormalities with age was shown in 2 patients by Frame et al. (1977) and Scott (1978). Electrocoagulation or the injection sclerosing agents have not to our knowledge bee tried. In rare cases surgery may be needed. Conside ing the benign course of the lesions we believe thgt patients should be treated with iron replacement and blood transfusions if necessary.

\section{References}

Frame, B., RaO, D.S., Ohorodnik, J.M. \& KWA, D.M. (197.9 Gastrointestinal hemorrhage in Turner syndrome. Archives \& Internal Medicine, 137, 691.

HADDAD, H.M. \& WILKINS, L. (1959) Congenital anomalies assocht ated with gonadal aplasia. Pediatrics, 23, 885.

Lisser, H., CURTIS, L.E., EsCamilla, R.F. \& Goldberg, M\$. (1947) Congenitally aplastic ovaries. Journal of Clinical Endocrinology, 7, 665 .

ROSEN, K.M., SIROTA, D.K. \& MARINOFF, S.C. (1967) Gastrointes nal bleeding in Turner's syndrome. Annals of Internal Medic 67, 145.

Rutlin, E., Wisloff, F., Myren, J. \& Serck-Hanssen, A. (19\%) Intestinal telangiectasia in Turner's syndrome. Endoscopo 86.

ScoTt, T. (1968) Turner's syndrome and vermiform phlebect the bowel. Transactions of the American Clinical and Climan cal Association, 79, 45.

TURNER, H.H. (1938) A syndrome of infantilism. congenital webb neck and oubitus valgus. Endocrinology, 23, 566.

(Accepted 17 June 1982) 